\title{
MYOCARDIAL DEPRESSANT ACTIVITY OF A NEWLY SYNTHESISED DIHYDROPYRIMIDINE DERIVATIVE 5-ACYL-6-METHYL-4-PHENYL-2-S-ETHYL-1, 4-DIHYDROPYRIMIDINE (BK-vi) IN COMPARISON WITH NIFEDIPINE
}

\author{
SHALINI SALWAN ${ }^{1 *}$, POONAM SALWAN ${ }^{2}$, WALIA R. ${ }^{3}$, BAJAJ V.K. $^{4}$ AND KAUR B. ${ }^{5}$ \\ 1Department of pharmacology ,PIMS, Garha Road Jalandhar, Panjab, India \\ 2Department of pharmacology, Manav Rachna Dental College, Faridabad, Haryana, India. \\ ${ }^{3}$ Department of pharmacology, MMIMSR, Mullana, Ambala, India. \\ ${ }^{4}$ Department of pharmacology, GMC, Patiala, India. \\ ${ }^{5}$ Department of chemistry, Punjabi University, Patiala, India. \\ *Corresponding Author: Email- drshalinisalwan@yahoo.co.in
}

Received: February 20, 2012; Accepted: March 09, 2012

\begin{abstract}
-
Objective- To investigate the myocardial depressant activity of a newly synthesised dihydropyrimidine derivative 5-acyl-6-methyl-4-phenyl-2 -S-ethyl-1,4-dihydropyrimidine (BK - vi) and comparing with nifedipine on Isolated perfused rabbit heart.

Material and Methods- Effects of the test compound BK-vi on the amplitude,heart rate and coronary flow on isolated perfused rabbit heart was compared with nifedipine.Observations were made with increasing concentrations of BK-vi and Nifedipine with dimethylsulfoxide (DMSO) as the solvent.Six preparations were used for each dose of BK-vi and nifedipine. Heart rate ,amplitude and coronary flow were noted down every minute for five minutes after injection of each drug and control.

Results- On comparing the effects of BK-vi and nifedipine, it was found that both had a negative inotropic and negative chronotropic effect. Compound BK -vi did not produce significant effect on heart rate at all the four doses. In comparison, nifedipine produced a significant to highly significant decrease in heart rate.Significant decrease in amplitude with BK-vi was seen at dose of 7.29 X 10-4M and 14.5 X 10-4M by $42 \%$ and $56.98 \%$ respectively and in coronary flow by $39.95 \%$ at dose of $14.5 \times 10-4 \mathrm{M}$.Nifedipine significantly decreased heart rate and amplitude at all doses with cardiac arrest at $4.6 \times 10-5 \mathrm{M}$.A significant increase in coronary flow was seen with nifedipine by $9.4 \%$ and $13 \%$ at doses of $0.5 \times 10-5 \mathrm{M}$ and $1.15 \times 10-5 \mathrm{M}$ respectively though this property was lost at higher doses.On comparison, BK-vi produced significant myocardial depression at much higher dose than nifedipine.

Conclusion- BK-vi has calcium channel blocking activity like nifedipine and produced less potent myocardial depression in comparison with nifedipine.
\end{abstract}

Key words- Dihydropyrimidines, Voltage dependent calcium channels, Nifedipine, Dihydropyridines

Citation: Shalini Salwan, et al (2012) Myocardial Depressant Activity of a Newly Synthesised Dihydropyrimidine Derivative 5-acyl-6-methyl4-phenyl-2-S-ethyl-1, 4-dihydropyrimidine (bk-vi) in comparison with nifedipine. International Journal of Medical and Clinical Research, ISSN:0976-5530 \& E-ISSN:0976-5549, Volume 3, Issue 3, pp.-132-135.

Copyright: Copyright@2012 Shalini Salwan, et al. This is an open-access article distributed under the terms of the Creative Commons Attribution License, which permits unrestricted use, distribution, and reproduction in any medium, provided the original author and source are credited.

\section{Introduction}

Modern drug discovery involves screening small molecules for their ability to bind to a preselected protein target as well as to modulate a biological pathway in cells [1].The demand for diverse compound libraries for screening in drug discovery is the driving force behind the development of new technologies for rapid parallel and combinatorial synthesis [2].Bignelli in 1893 first described the synthesis of 6-methyl-4-substituted phenyl 2-oxo-1,2,3,4tetrahydropyrimidine-5-carboxylic acid ethyl esters by condensation of an aldehyde, urea and ethyl acetoacetate [3] .DHP (Dihydropyridines) and DHPMs(Dihydropyrimidines) represent important and extensively studied compounds belonging to the class of calcium channel blockers.Many researchers have determined the synthetic routes and biological activities of these compounds. These developments led to the pharmacological evaluation of these compounds [4]. Much interest has been shown in the design of Bignelli-like compounds which are valuable substitutes for the nifedipine and other 1,4-dihydropyridine drugs [5], regarded as aza-analogues of nifedipine related dihydropyridines [6].Out of the diverse range of biological activities shown by dihydropyrimidines, most notable is the cardiovascular activity that compares favourably with activity shown by structurally related drugs amlodipine, nicardipine. A reasonable pharmacophore model for DHP/DHPM calcium channel modulators has been proposed 
featuring a boat-like conformation of DHP/DHPM ring, an axially positioned aryl ring and an ester group at $\mathrm{C} 5$ oriented cis with respect to $\mathrm{C} 5=\mathrm{C} 6$ double bond [7].

Dihydropyrimidines uniquely designed to unambiguously establish structural and conformational determinants for DHP receptor occupation were prepared and examined for calcium channel modulation. The enantiomers of dihydropyrimidines having up - oriented pseudo-axial aryl group(normal DHP boat) elicit calcium channel antagonistic activity [8]. Compounds with a longer chain at N3 exhibited less potent vasodilating activity while compounds with shorter length have more potent vasodilator activity [9] Since a wide range of biological activity is associated with 1,4- dihydropyrimidines and a slight modification in structure can result in qualitative as well as quantitative changes in their activity, this study is an effort to develop such compounds with the aim of having improved activity and lesser toxicity compared with other calcium channel blockers in clinical use.

One such compound 5-acyl-6-methyl-4-phenyl-2-S-ethyl-1,4dihydropyrimidine (BK- vi), has been taken up for the present study to find out its cardiovascular effects and calcium channel blocking activity.

\section{Material and Methods \\ Test Compound (bk-vi)}

Test compound 5-acyl-6-methyl-4-phenyl-2-S-ethyl-1,4dihydropyrimidine ( BK vi),(Molecular weight-274) was obtained from department of chemistry,Punjabi university,Patiala.A mixture of benzaldehyde $(0.01$ mole, $1.06 \mathrm{gm})$, thiourea $(0.01 \mathrm{~mole}, 0.76$ $\mathrm{gm})$, acetylacetone $(0.015 \mathrm{~mole}, 1.5 \mathrm{ml})$ and concentrated $\mathrm{HCl}(3-$ 4 drops) in absolute alcohol (10ml) was irradiated at $30 \%$ microwave power level. The tetrahydropyrimidine obtained was separated, dissolved in $\mathrm{NaOH}$ solution and to this mixture,diethyl sulfate was added. The solid product separated was confirmed by taking its IR, NMR, UV and mass spectra [9].Compound BK-vi was found to be soluble in dimethylsulfoxide(DMSO).

\section{Drugs and chemicals}

DMSO (Dimethylsulfoxide) was used as a solvent for compound BK-vi and nifedipine. Other chemicals and agents used were of pure analytical grade and obtained from local suppliers.

\section{Animals}

Adult healthy rabbits of either sex weighing between $1.5-2.5 \mathrm{~kg}$ were used in this study. They were provided uniform environmental conditions and diet. The diet comprised of green leafy vegetables, grass, soaked grams and milk. The care and maintenance of the animals was as per the approved guidelines of the Committee For the Purpose of Control and Supervision of Experiments on Animals (CPCSEA), India. All the animal procedures were approved by the Animal Ethical Committee of the establishment. Isolated Perfused Rabbit Heart was used for the present study.

\section{Procedure Isolated Perfused Rabbit Heart}

Heart Rate: The rabbit heart was mounted as per the methods described by Burn (1952) and Perry (1970). The animals were stunned and bled through carotid arteries. The chest was opened and heart along with an inch of ascending aorta was cut and trans- ferred to a petri-dish containing oxygenated Ringer Locke solution at $37^{\circ} \mathrm{C}$. The ventricles were squeezed to remove all blood in order to prevent development of thrombi in the vessels.

The heart was mounted in the Langendorff's assembly. The drug solutions were injected through a polyethylene tube inserted into the rubber tube perfusing the heart. The apex of the heart was attached to the Starling's heart liver with the help of a bent pin passed through the apex and connected to a thread. Baseline recordings were taken after giving a stabilisation time of around 15 minutes. The drugs were administered through the polyethylene tube and each time, it was followed by injection of $0.2 \mathrm{ml}$ of Ringer Locke solution to ensure complete displacement of the drug. The sensitivity was checked every time by administration of adrenaline $2 \mu \mathrm{g}[10,11]$. Also the effect of test compound was compared with vehicle alone and nifedipine as a control.

Heart rate was counted continuously for 5 minutes after the injection of each drug including the vehicle. The rate was noted down every minute in the five minutes and effect observed. Six such experiments were conducted and mean value calculated.

Amplitude: The amplitude was observed continuously for five minutes after injection of each drug including the vehicle. Six such experiments were conducted and mean value calculated.

Coronary flow: After injection of each drug and control, coronary flow was estimated for five minutes with flow rate noted down every minute. Six such experiments were conducted.

\section{Statistics}

Mean value and standard error for all parameters were determined separately and put in tables as mean \pm SE and as percentage change. Statistical significance of the difference at various concentrations,before and after was analysed using Student's paired 't' test.

\section{Results \\ Effect on isolated perfused rabbit heart}

Effect of the test compound BK-vi on the amplitude, heart rate and coronary flow was observed and compared with that of nifedipine. Solutions of compound BK-vi and nifedipine were made in Dimethyl sulfoxide (DMSO) in different concentrations, so that a fixed volume $(0.2 \mathrm{ml})$ was given for every dose.

\section{Effect on Heart Rate}

Administration of dimethylsulfoxide (DMSO) alone led to mean percentage increase in heart rate by $3.33 \%(p>0.05)$ (Table I), "(Fig. 1)"

Nifedipine alone caused highly significant to very highly significant decrease in heart rate. The mean percentage decrease was $4.31 \%(p<0.01), 20.75 \%(p<0.001)$ and $25.17 \%(p<0.001)$ at doses of $0.05 \times 10-4 \mathrm{M}, 0.11 \times 10-4 \mathrm{M}$ and $0.23 \times 10-4 \mathrm{M}$ respectively. A complete cardiac arrest was seen with $0.46 \times 10-4 \mathrm{M}$ dose (Table IV), "(Fig.2)"

In comparison to nifedipine, BK-vi did not show significant effect on heart rate at all the four doses used. (Table I), "(Fig.1)"

Effect on amplitude of contraction

With $0.2 \mathrm{ml}$ of DMSO, the solvent, an increase in the amplitude was observed. The mean percentage increase in the amplitude was $42.88 \%$ ( $>>0.05$ ) (Table II)," (Fig. 1)".

Nifedipine showed significant decrease in amplitude with all the doses. The mean percentage decrease in amplitude was $17.97 \%$ 
$(p<0.001), 57.39 \% \quad(p<0.001), 91.08 \%(p<0.001)$ at doses of $0.05 \times 10-4 \mathrm{M}, 0.11 \times 10-4 \mathrm{M}$ and $0.23 \times 10-4 \mathrm{M}$ respectively. A complete cardiac arrest was seen at $0.46 \times 10-4 \mathrm{M}$ dose (Table IV)," (Fig.2)"

In comparison to Nifedipine, BK-vi showed decrease in amplitude of contraction at higher doses. The mean percentage decrease in amplitude was $42 \%$ and $56.98 \%$ at doses of $7.29 \times 10-4 M(p<0.1)$ and $14.5 \times 10-4 \mathrm{M}(p<0.01)$ respectively. (Table II)," (Fig. 1$) "$

\section{Effect on Coronary Flow}

Dimethyl sulfoxide (DMSO) given alone in a dose of $0.2 \mathrm{ml}$ caused an increase in the coronary flow. The mean percentage increase in the coronary flow was $6.35 \%$ ( $p>0.05$ ) (Table III)," (Fig.1)"

Nifedipine, however led to a significant increase in the coronary flow at lower doses. The mean percentage increase was $9.40 \%$ $(p<0.001), 13.00 \% \quad(p<0.001)$ with doses of $0.05 \times 10-4 \mathrm{M}$ and $0.11 \times 10-4 \mathrm{M}$ respectively. A mean percentage decrease of $4.19 \%$ $(p<0.001)$ and $13.09 \%(p<0.001)$ was observed at higher doses of $0.23 \times 10-4 \mathrm{M}$ and $0.46 \times 10-4 \mathrm{M}$ respectively (Table IV)," (Fig.2)"

With compound BK-vi, no significant increase or decrease in coronary flow was observed except at higher dose where a significant reduction in coronary flow was observed. The mean percentage decrease was $39.95 \%(p<0.01)$ at dose of $14.5 \times 10-4 \mathrm{M}$. (Table III)," (Fig.1)"

Table l- mean effect of increasing dose of bk-vi and that of Dimethyl Sulfoxide (solvent) on heart rate (beats/minute) of isolated perfused Rabbit Heart $(n=6)$

\begin{tabular}{|lllll|}
$\begin{array}{l}\text { Dose } \\
(\mu \mathrm{g} / \mathrm{ml})\end{array}$ & $\begin{array}{l}\text { DMSO }(0.1 \mathrm{ml} \text { dose) } \\
(\text { Mean } \pm S E)\end{array}$ & $\begin{array}{l}\text { BK VI } \\
(\text { Mean } \pm \text { SE) }\end{array}$ & $\begin{array}{l}\text { Mean \%age } \\
\text { change }\end{array}$ & P value \\
\hline 50 & $\begin{array}{l}7.04 \pm 3.55 \\
(p>0.05)\end{array}$ & $-13.66 \pm 13.24$ & $1.69^{-}$ & $(p>0.05)$ \\
100 & $\begin{array}{l}7.04 \pm 3.55 \\
(p>0.05)\end{array}$ & $-8.33 \pm 7.14$ & $6.29^{-}$ & $(p>0.05)$ \\
& $\begin{array}{l}7.04 \pm 3.55 \\
200\end{array}$ & $-16.17 \pm 10.08$ & $13.20^{-}$ & $(p>0.05)$ \\
400 & $\begin{array}{l}(p>0.05) \\
7.04 \pm 3.55\end{array}$ & $-14.50 \pm 15.24$ & $20.22^{-}$ & $(p>0.05)$ \\
& $(p>0.05)$ & & & \\
\hline
\end{tabular}

Table II- mean effect of increasing dose of bk-vi and that of Dimethyl Sulfoxide (solvent) on AMPLITUDE $(\mathrm{mm})$ of isolated perfused Rabbit Heart $(n=6)$

\begin{tabular}{|lllll|}
$\begin{array}{l}\text { Dose } \\
(\mu \mathrm{g} / \mathrm{ml})\end{array}$ & $\begin{array}{l}\text { DMSO }(0.1 \mathrm{ml} \text { dose) } \\
(\text { Mean } \pm S E)\end{array}$ & $\begin{array}{l}\text { BK VI } \\
(\text { Mean } \pm S E)\end{array}$ & $\begin{array}{l}\text { Mean \%age } \\
\text { change }\end{array}$ & P value \\
50 & $\begin{array}{l}9.7 \pm 3.9 \\
(p>0.05)\end{array}$ & $-9.5 \pm 7.9$ & $20.42^{-}$ & $p>0.05$ \\
100 & $\begin{array}{l}9.7 \pm 3.9 \\
(p>0.05)\end{array}$ & $-6.5 \pm 5.6$ & $7.23^{-}$ & $p>0.05$ \\
200 & $\begin{array}{l}9.7 \pm 3.9 \\
(p>0.05)\end{array}$ & $-16.3 \pm 3.7$ & $42.00^{-}$ & $p<0.01$ \\
400 & $\begin{array}{l}9.7 \pm 3.9 \\
(p>0.05)\end{array}$ & $-15.5 \pm 4.1$ & $56.98^{-}$ & $p<0.01$ \\
\hline
\end{tabular}

Table III- mean effect of increasing dose of bk-vi and that of Dimethyl Sulfoxide (solvent) on CORONARY FLOW ( $\mathrm{ml} / \mathrm{min})$ of isolated perfused Rabbit Heart $(n=6)$

\begin{tabular}{|lllll|}
$\begin{array}{l}\text { Dose } \\
(\mu g / m l)\end{array}$ & $\begin{array}{l}\text { DMSO }(0.1 \mathrm{ml} \text { dose }) \\
(\text { Mean } \pm S E)\end{array}$ & $\begin{array}{l}\text { BK VI } \\
(\text { Mean } \pm S E)\end{array}$ & $\begin{array}{l}\text { Mean \%age } \\
\text { change }\end{array}$ & P value \\
\hline 25 & $\begin{array}{l}0.05 \pm 0.2 \\
(p>0.05)\end{array}$ & $-0.28 \pm 0.36$ & $2.98^{-}$ & $p>0.05$ \\
50 & $\begin{array}{l}0.05 \pm 0.2 \\
(p>0.05)\end{array}$ & $-0.58 \pm 0.27$ & $13.83^{-}$ & $p>0.05$ \\
100 & $\begin{array}{l}0.05 \pm 0.2 \\
(p>0.05)\end{array}$ & $+0.32 \pm 0.30$ & $12.46^{-}$ & $p>0.05$ \\
200 & $\begin{array}{l}0.05 \pm 0.2 \\
(p>0.05)\end{array}$ & $-1.73 \pm 0.45$ & $39.95^{-}$ & $p<0.01$ \\
\hline
\end{tabular}

Table IV- mean \%age change in heart rate(beats/minute), amplitude $(\mathrm{mm})$ and coronary flow $(\mathrm{ml} / \mathrm{min})$ with increasing dose of nifedipine on isolated perfused Rabbit Heart $(n=6)$

\begin{tabular}{|llll|}
$\begin{array}{l}\text { Dose } \\
(\mu \mathrm{g} / \mathrm{ml})\end{array}$ & $\begin{array}{l}\text { Heart rate(Beats/ } \\
\mathrm{min} .)\end{array}$ & Amplitude $(\mathrm{mm})$ & $\begin{array}{l}\text { Coronary Flow } \\
(\mathrm{ml} / \mathrm{min} .)\end{array}$ \\
\hline 2 & $4.31^{-}$ & $17.97^{-}$ & $9.40-$ \\
& $p<0.01$ & $p<0.001$ & $p<0.001$ \\
4 & $20.75^{-}$ & $57.39^{-}$ & $13.00-$ \\
& $p<0.001$ & $p<0.001$ & $p<0.001$ \\
8 & $25.17^{-}$ & $91.08^{-}$ & $4.19^{-}$ \\
& $p<0.001$ & $p<0.001$ & $p<0.001$ \\
16 & $100^{-}$ & $100^{-}$ & $13.09^{-}$ \\
& $p<0.001$ & $p<0.001$ & $p<0.001$ \\
\hline
\end{tabular}

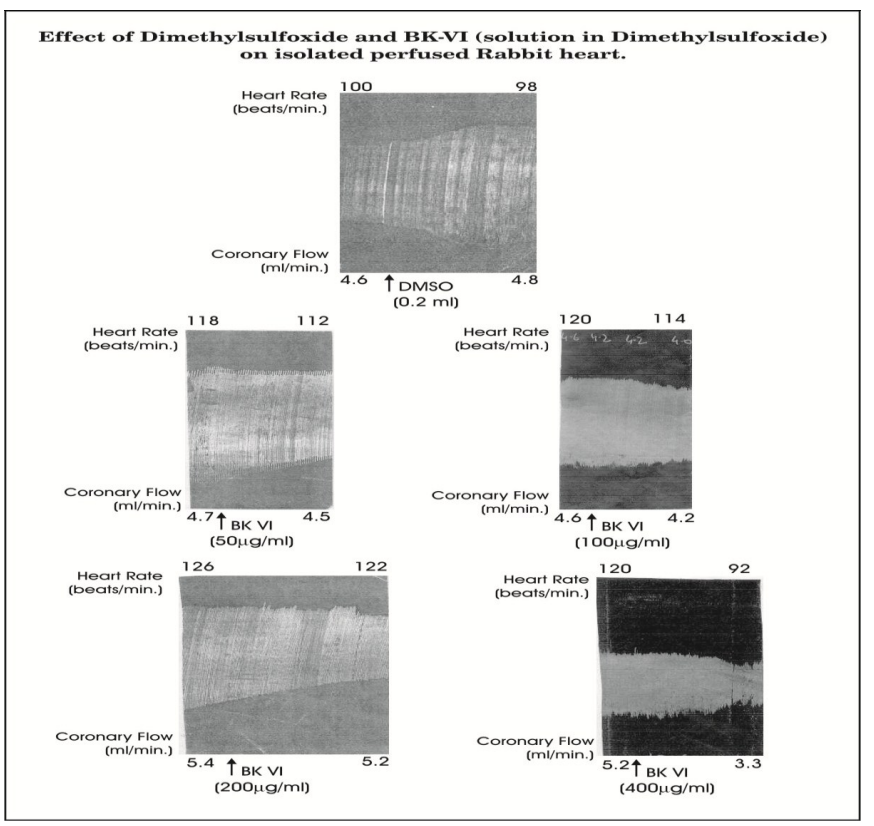

Fig. 1-

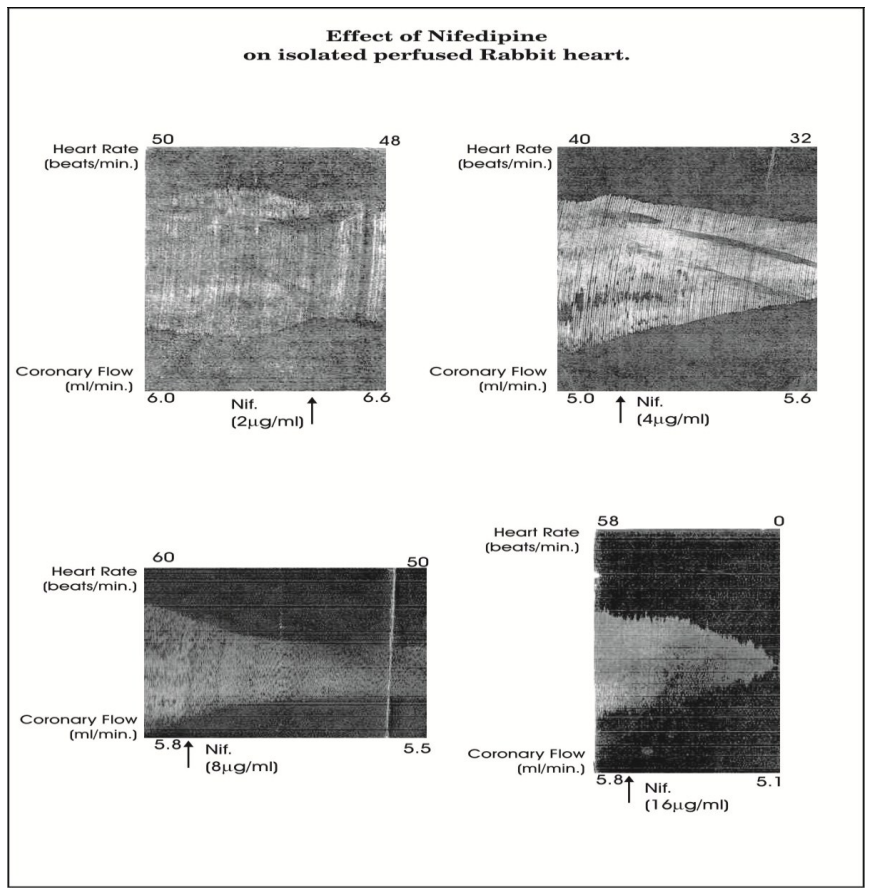

Fig. 2- 


\section{Discussion}

Recently, 1, 4 - dihydropyrimidine - 5 carboxylate compounds have been presented as valuable substitutes [12] for nifedipine and other dihydropyridine drugs [5], clinically used in the treatment of cardiovascular disease. In the present study, the pharmacological actions of a newly synthesised dihydropyrimidine derivative 5-acyl-6-methyl-4-phenyl-2-S-ethyl-1, 4-dihydropyrimidine (BK -vi) were studied on cardiovascular system. 'In vitro' preparation of isolated perfused rabbit heart was used for serving that purpose.Six experiments were conducted with different concentrations of BK-vi and nifedipine in each parameter.

Calcium channel blockers can reduce or block impulse generation in the SA node and conduction in the AV node. Although nifedipine reduces the slow inward $\mathrm{Ca} 2+$ current in a dose dependent manner, it does not affect the rate of recovery of the slow $\mathrm{Ca} 2+$ channel [13]. For testing the effect on cardiac muscle and the coronaries, isolated perfused rabbit heart was used. The effect of the test compound BK-vi was compared with that of prototype dihydropyridine compound nifedipine, BK-vi was found to be less potent pertaining to depressant action on amplitude of contraction of the heart and on the heart rate and these depressant effects appeared comparatively at a higher dose range with test compound BK-vi.

It has been shown that dihydropyrimidines mimic the biological activity of dihydropyridines when compared directly with similarly substituted 2-heteroalkyl-dihydropyridines, those were found to be 30-fold less active [14]. These observations are in agreement with our results, where our compound BK-vi, which is also a dihydropyrimidine derivative, shows myocardial depressant effect similar to nifedipine, a dihydropyridine calcium channel blocker and BK-vi is a less potent myocardial depressant as compared to nifedipine.

Calcium channel blockers have vasodilatory effect on the arterial resistance vessels and coronary vessels [15]. With test compound BK-vi, there was significant reduction in the coronary flow at high dose of $14.5 \times 10-4 \mathrm{M}$. Nifedipine, on the other hand caused a significant increase in the coronary flow although this effect was lost at higher doses $(0.23 \times 10-4 \mathrm{M}$ and $0.46 \times 10-4 \mathrm{M})$ and instead a decrease in coronary flow was observed. Thus, it can be concluded that BK-vi has negative inotropic and negative chronotropic effect on mammalian heart and there is decrease in the coronary flow which is significant at high doses. Since some drugs show more pronounced effect in disease and in pathophysiological model than in physiological condition [16], there is therefore a need for appropriate pathophysiological models, the predictive value of which, however, may be affected by species differences.
- SE - Standard Error

- $\mathrm{ml}$ - millilitre

- $\mu g$ - microgram

- M - Moles

- $\%$ - Percentage

- SA Node - Sinoatrial node

- AV Node - Atrioventricular node

- Ca2+ - Calcium ion

\section{References}

[1] Schereiber Stuart L. (2000) Science, 287(5460), 1964-1969.

[2] Dallinger Dorris and Kappe C. Oliver (2005) Pure Appl. Chem., 77,155-161.

[3] Biginelli P. (1893) Gazz. Chim. Ital., 23, 360.

[4] Kumar B.R Prashantha, Masih Pankaj, Karthikeyan E., Bansal Ankur, Vijayan Suja, Pottekad (2010) Medicinal Chemistry Research, 19, 344-363.

[5] Bossert F., Meyer H., Wehinger E. (1981) Angen Chem Int Ed Engl, 20, 762-769

[6] Baldwin J.J., Claremon D.A., Mcclure D.E. (1987) US patent 4, 609, 494 Chem Abstr, 106,18636d.

[7] Kappe C.O. (1993) Tetrahydron, 49, 6937-6963.

[8] Rovnyak G.C., Kimball D., Beyer B. (1995) J. Med Chem ,38 (1), 119-129.

[9] Kaur J. (1999) A post-graduate thesis, Deptt. Of Chemistry, Punjabi University, Patiala.

[10]Perry W.L.M. (1970) E \& S. Livingstone, Edinburgh, 2,116.

[11]Ghosh M.N. (2005) 2nd ed.Calcutta:Scientific book agency, 34,10,22-23, 90, 92-93,130-131.

[12]Atwal K.S., Rovnyak G.C., Kimball S.D. (1990 a) J. Med Chem, 33, 2629-2635.

[13]Kohlhardt M. and Fleckenstein A. (1977) NaunynSchemiedeberg's Arch Pharmacol, 298, 267-272.

[14]Atwal K.S., Rovnyak G.C., Schwartz J. (1990b) J. Med Chem, 33, 1510-1515.

[15]Kerins D.M., Robertson R.M. and Robertson D. (2001) Goodman and Gilman's, "The pharmacological basis of therapeutics", The McGraw-Hill Companies, Inc, USA, 10, 853-860.

[16]Godgraind T., Miller R.C. and Wibo M. (1986) Pharmacol Rev,38, 321-416.
Abbrevations
- DHP - Dihydropyridines
- DHPM - Dihydropyrimidines
- CCB's - Calcium channel blockers
- DMSO - Dimethyl sulfoxide
- $\mathrm{HCl}$ - Hydrochloric acid
- $\mathrm{NaOH}$ - Sodium Hydroxide
- IR - Infrared
- NMR - Nuclear Magnetic Resonance
- UV - Ultraviolet 